porque realiza un análisis crítico y detallado de la regulación vigente; en segundo lugar, porque destaca los conflictos jurídicos que ha planteado su aplicación y señala tanto las lagunas que presenta la regulación como las discordancias que se aprecian entre las soluciones jurisprudenciales adoptadas $\mathrm{y}$ la realidad social existente, y, en tercer lugar, porque aporta propuestas concretas para suplir las lagunas, corregir las discordancias y, en definitiva, mejorar el régimen jurídico de la figura estudiada.

\section{M. ${ }^{a}$ Olaya Godoy VÁzQuez Dpto. Derecho Constitucional Facultad de Derecho. UCM}

\title{
Rafael AlCÁCER GUIRAO, La libertad del odio. Discurso intolerante y protección penal de minorías, Madrid, Marcial Pons, 2020, 273 pp. https://dx.doi. org/10.5209/foro.77703.
}

Las expresiones «discurso del odio»y «delito de odio» se han convertido en omnipresentes en nuestra sociedad. No solo se recurre a ellas de manera constante en el debate político y en los medios de comunicación, sino también en ámbitos policiales y judiciales ${ }^{1}$. Por otra parte, casi a diario nos encontramos con nuevas denuncias por delitos de odio presuntamente cometidos contra colectivos tan dispares como los cazadores, la policía, los militantes de un partido político o los españoles, entre otros muchos. Sin embargo, la utilización exacerbada de estos términos no es sino una evidencia de la confusión que existe en todo lo que se refiere a esta materia. La presente obra del profesor Alcácer Guirao contribuye significativamente a su clarificación.

El autor comienza esbozando, en un capítulo introductorio, las líneas maestras de las diferentes cuestiones que se van a abordar en la obra, además de condensar en unas pocas páginas algunos de los casos más célebres, a escala internacional, de condena penal por incitación al odio. De esta forma se evidencia que la punición de este tipo de conductas es un fenómeno global, si bien, como demostrará en el siguiente capítulo, existen hondas diferencias entre el modelo europeo y el estadounidense.

${ }^{1}$ En el ámbito judicial se ha llegado a utilizar el término «discurso del odio» para referirse al discurso enaltecedor del terrorismo, a pesar de las hondas diferencias entre uno y otro. Sobre esta cuestión, vid. M. Cancio Melí y J. A. Díaz López, ¿Discurso de odio y/o discurso terrorista? Música, guiñoles y redes sociales frente al art. 578 del Código Penal, Cizur Menor, Aranzadi, 2019. 
En lo que respecta al primero de estos modelos, el autor destaca cómo la tragedia del Holocausto ha influido de manera determinante en el concepto de libertad de expresión que maneja el Tribunal Europeo de Derechos Humanos, concepto que entraña no solo la existencia, en el art. 10.2 del Convenio Europeo de Derechos Humanos (CEDH), de una serie de límites a este derecho, sino también la posibilidad de excluir a limine el ejercicio del mismo cuando se considere que incurre en abuso de derecho con base en el art. 17 $\mathrm{CEDH}$. Tanto uno como otro han sido empleados en diversas ocasiones para situar al discurso del odio extramuros de la libertad de expresión. Se trata, en definitiva, de un modelo propio de una democracia militante que se sustenta en la célebre paradoja popperiana de la tolerancia, resumida en la conocida máxima de los jacobinos de la Revolución francesa: «pas de liberté pour les ennemis de la liberté» («no hay libertad para los enemigos de la libertad»).

Por el contrario, el modelo estadounidense se fundamenta en el carácter cuasi ilimitado de la libertad de expresión consagrada en la Primera Enmienda de su Constitución. El autor encuentra la razón de esta regulación en la suspicacia hacia la injerencia del Estado en los derechos del individuo, propia del liberalismo originario en el que se enmarca la Constitución estadounidense. Así, el único límite al discurso con relevancia pública sería la incitación directa e inmediata a la violencia (el llamado clear and present dan$g e r)^{2}$. En cuanto al discurso carente de esta relevancia, sí que podría limitarse cuando consista en proferir insultos o expresiones agresivas (fighting words) a la cara del interlocutor, pero con la condición de que las limitaciones sean content-neutral, es decir, neutrales en su contenido; así, no sería posible prohibir por ley expresiones de índole racista o sexista y dejar impunes las expresiones agresivas de signo opuesto, porque se estaría restringiendo el discurso por razón del contenido del mismo.

Finalizada la comparación entre ambos modelos, el autor se centra en el siguiente capítulo en desentrañar los fundamentos de la libertad de expresión desde el

\footnotetext{
${ }^{2}$ Con todo, en ocasiones esta regla se ha puesto en entredicho como consecuencia de ciertas restricciones a la libertad de expresión en diferentes periodos de la historia estadounidense bajo la excusa de la existencia de una situación excepcional, como la Guerra Fría o la llamada «guerra contra el terrorismo» planteada después de los atentados del 11-S. Sobre esta cuestión, vid. T. RodrígueZ MontaÑÉs, Libertad de expresión, discurso extremo y delito, Valencia, Tirant lo Blanch, 2012.
} 
punto de vista de la filosofía política. Comienza ahondando en la concepción liberal de la libertad de expresión, distinguiendo entre el liberalismo más individualista o libertario, que concibe este derecho desde el punto de vista de la autonomía del individuo frente al Estado y se opone a cualquier limitación del mismo con base en el free market place of ideas («libre mercado de las ideas»), y el liberalismo contractualista, que, partiendo del carácter esencial de la libertad de expresión para una sociedad democrática, entiende que resulta necesario en ocasiones intervenir en este «libre mercado» para garantizar que determinados grupos sociales puedan acceder al debate público en las mismas condiciones que los demás. Cercano a esta última teoría se encuentra el republicanismo cívico, que pone especial énfasis en la necesidad de que el Estado intervenga en la discusión pública para amplificar la voz de los grupos minoritarios y coartar aquellos discursos intolerantes que arremeten contra dichos grupos. Esta defensa de la restricción del discurso del odio es también un rasgo propio de las teorías comunitaristas, que abogan por una protección de la identidad grupal frente a las conductas difamatorias contra colectivos, y de las multiculturalistas, que fundamentan dicha restricción o bien en la consideración del ataque a la identidad cultural del grupo como un atentado a la dignidad de sus miembros, o bien en la erosión de la reputación de los miembros del grupo provocada por este tipo de discursos. En conclusión, la postura de cada una de estas teorías en relación con la libertad de expresión es explicada profusamente en el capítulo, que finaliza con una reflexión acerca de la democracia deliberativa habermasiana, la cual, a la vez que otorga a la libertad de expresión una posición primordial, defiende la eventual intervención del Estado para promover valores democráticos y facilitar la participación de las minorías en el debate público.

En el siguiente capítulo, Alcácer se adentra en la siempre espinosa tarea de deslindar el derecho de libertad de expresión de lo que se encuentra extramuros del mismo. Desde el inicio muestra su disconformidad con la doctrina constitucional en la materia, de acuerdo con la cual el discurso del odio debe estar, en todo caso, excluido del ámbito de este derecho. Frente a estos rígidos criterios, dudosamente compatibles con el principio de proporcionalidad, el autor aboga por una solución casuística, que exige la ponderación en cada supuesto de los diferentes derechos y bienes constitucionales en liza. 
Lo anterior requiere preguntarse por cuáles son los bienes dignos de protección constitucional que pueden resultar dañados por el discurso del odio y que legitimarían su restricción. Así, Alcácer desecha que los conceptos de dignidad y honor puedan justificar la imposición de límites a este tipo de discurso: el primero, por su excesiva indeterminación y amplitud; el segundo, entre otras razones, porque la difamación contra la totalidad de un grupo social disminuye el daño causado a cada uno de sus miembros, de manera que la afectación de su derecho al honor será mucho menor que si la difamación se dirigiera individualmente a cada uno de ellos ${ }^{3}$. Frente a ambos, el autor identifica el auténtico fundamento de la lesividad del discurso del odio en los comportamientos discriminatorios que puede acarrear hacia los grupos afectados por el mismo.

Partiendo de esta última premisa, el autor finaliza su obra analizando cuándo procede el castigo penal del discurso del odio, que en nuestro ordenamiento se produce principalmente de la mano del delito de incitación al odio del art. 510 del Código Penal. Ya en el capítulo anterior Alcácer toma partido en favor de la protección exclusiva frente al discurso del odio de los grupos tradicionalmente minoritarios o vulnerables, que son los únicos que pueden correr el riesgo de sufrir un trato discriminatorio si este tipo de discursos se extienden en la sociedad. Una postura con la que nos identificamos plenamente, pero que, por desgracia, no es ni la escogida por el legislador ni la preponderante en la persecución penal de este delito; así, continuamente nos encontramos en la práctica forense con imputaciones por supuestos delitos de incitación al odio contra la Casa Real, contra dirigentes de partidos políticos o contra miembros de las Fuerzas y Cuerpos de Seguridad del Estado, lo que acaba convirtiendo a dicho delito en un instrumento de protección de las instituciones y de silenciamiento de la crítica ciudadana ${ }^{4}$. Por si esto fuera poco, la Circular 7/2019 de la Fiscalía General del Estado, que establece una serie de pautas de interpretación de los deli-

3 Sobre la menor lesividad del atentado contra el honor cuando se dirige contra un colectivo determinado, vid. C. López PEREgRín, La protección penal del honor de las personas jurídicas y los colectivos, Valencia, Tirant lo Blanch, 2000.

${ }^{4}$ En defensa de esta misma postura se posiciona P. LauRenzo Copello, «Sentimientos religiosos y delitos de odio: un nuevo escenario para unos delitos olvidados», en P. DE La Cuesta Aguado et al. (eds.), Liber Amicorum. Estudios jurídicos en homenaje al profesor Dr. b. c. Juan M. ${ }^{a}$ Terradillos Basoco, Valencia, Tirant lo Blanch, 2018, pp. 1295-1296. 
tos de odio, se posiciona a favor de la protección penal de los grupos hegemónicos, alcanzando su culmen en la inefable afirmación de la circular de que «una agresión a una persona de ideología nazi, o la incitación al odio hacia tal colectivo, puede ser incluida en este tipo de delitos». Frente a esta grotesca tergiversación del sentido del delito, Alcácer aboga por una interpretación del precepto tendente a excluir a los grupos dominantes de la protección otorgada por el mismo.

Por otra parte, y ahondando en la interpretación restrictiva del delito de odio, el autor entiende que el discurso del odio solo deberá ser penalmente punible cuando comporte un riesgo para la seguridad existencial de los grupos protegidos. Considera que esta postura es la más acertada porque, en primer lugar, impide un adelantamiento excesivo de las barreras de defensa penal; en segundo lugar, evita que este precepto penal se convierta en una suerte de guardián de valores mayoritarios de la sociedad, lo que comportaría un silenciamiento no justificado de las opiniones disidentes, y, por último, no coarta las expresiones meramente ofensivas, las cuales también forman parte de la libertad de expresión. Para determinar cuándo un mensaje pueda suponer dicho riesgo, Alcácer se decanta por la aplicación del llamado test de Rabat ${ }^{5}$, elaborado en el marco del Plan de Acción de Rabat de Naciones Unidas de 2012 y que establece una serie de criterios para determinar cuándo el discurso del odio es penalmente castigable, tales como el contexto del mensaje, la relevancia social del emisor del mismo, el grado de difusión o la probabilidad de que el mensaje cale en la sociedad, con el consiguiente riesgo para los grupos que son blanco de esos discursos.

El profesor Alcácer, en definitiva, aboga en esta obra por una concepción del discurso del odio y de su castigo penal más cercana al modelo del clear and present danger estadounidense que al de la jurisprudencia de Estrasburgo, tendente a castigar los discursos antidemocráticos, xenófobos u homófobos por el mero hecho de serlo. El autor considera que estos últimos discursos son repudiables y deben ser combatidos, pero a través del debate y el contra discurso, y no por medio del Derecho penal, que debe reservarse para aquellos mensajes que realmente puedan poner en peli-

5 Disponible en https://www.ohchr.org/Documents/Issues/Opinion/Articles19-20/ ThresholdTestTranslations/Rabat_threshold_test_Spanish.pdf. 
gro a los grupos contra los que se dirigen. Como defensor acérrimo de la libertad de expresión, el autor se opone a quienes afirman, como rezaba aquel clásico eslogan maoísta, que «una sola chispa puede incendiar la pradera ${ }^{6} \mathrm{y}$ que es necesario apagarla cuanto antes. Frente a ellos, Alcácer nos recuer- da que esa chispa es la que enciende el motor de la democracia.

\author{
Alberto José Ferrari Puerta \\ Investigador Predoctoral FPU. \\ Dpto. Derecho Internacional, \\ Eclesiástico y Filosofía del Derecho \\ Instituto Universitario \\ de Ciencias de las Religiones. UCM
}

David Runciman, Así termina la democracia, Barcelona, Paidós, 2019, 304 pp. https://dx.doi.org/10.5209/foro. 77704 .

La ciencia política lleva tiempo preocupada por el presente y futuro de nuestras democracias ${ }^{1}$. La obra que se reseña aquí forma de parte de dicho acervo, está escrita por David Runciman, profesor de la Universidad de Cambridge, y es un ensayo lúcido, interesante y muy ameno de leer.

David Runciman plantea sus tesis ya al comienzo del libro: el mayor riesgo para las democracias es no saber los riesgos actuales que sufre. Para Runciman, ya no vamos a volver al siglo $\mathrm{Xx}$, los problemas que allí se dieron no son los que las democracias tienen hoy, ese marco de referencia está superado. De ahí que crea que «cuando la democracia se termine, probablemente nos sorprenderá la forma en que lo hará» (p. 11). Runciman nos dice que no es que la democracia esté tocando a su fin, sino que está atravesando su crisis de madurez.

Las principales diferencias entre la democracia de antes y la de ahora son diversas ${ }^{2}$. Por un lado, la violencia política no es la que era, por ello «nuestros impulsos más destructivos se manifiestan por otras vías» (p. 15). Por otro, la amenaza

${ }^{6}$ M. TSE-Tung, «Una sola chispa puede incendiar la pradera (5-I-1930)», en Obras Escogidas, t. I, Madrid, Fundamentos, 1974, pp. 125-138. Resulta curioso que una expresión similar fuera utilizada por la Corte Suprema estadounidense en la sentencia Gitlow v. New York (1925) para justificar la sanción impuesta a un individuo por publicar un manifiesto izquierdista.

${ }^{1}$ Citamos dos a título de ejemplo. Son los de Y. Mounk, El pueblo contra la democracia, Barcelona, Paidós, 2018, y S. Levitsky y D. Ziblatt, Cómo mueren las democracias, Barcelona, Ariel, 2018.

2 Sobre la democracia se ha encontrado un interesantísimo estudio en J. Keane, Vida y muerte de la democracia, México, Fondo de Cultura Económica, 2018. 